مجلة جامعة الهلك عبدالعزيز: الآداب و العلوم الانسانية، م26ع3 ص ص: 341- 360 360 (2018م)

DOI:10.4197/Art.26-3.14

\title{
The Acquisition of Arabic scrambling dative structures by English learners
}

\author{
Anwar Saad Al-Jadani \\ King Abdulaziz University- Jeddah, Saudi Arabra
}

\begin{abstract}
This paper represents an empirical study to investigate the ability of L2 learners to acquire structures that are not allowed by their L1 grammar. An experiment was made with 40 native speakers of English majoring at two proficiency levels: pre-intermediate and upper-intermediate. These participants completed written judgment tasks, which included 24 scrambling dative sentences, to judge their grammaticality in Arabic. The collected data was discussed based on the Full-Transfer/ Full Access approach and the Feature Reassembly Hypothesis. The statistical analysis showed no significant disparities between native speakers and L2 learners in acquiring L2 structures, which can be indicated as a sign of the fact that L2 learners acquired the structures that are not allowed in their L1.

Keywords: Dative alternation, prepositional dative construction, double objective dative construction, scrambling dative sentences, second language learners, the Full-Transfer/ Full Access approach, the Feature Reassembly Hypothesis.
\end{abstract}

\section{Introduction}

During the past decades, the effect of First Language (L1) on the acquisition of Second Language (L2) has been explored extensively. One of the issues addressed in L2 research concerns the influence of the divergence between the L1 and the L2 argument structures, which is one of the difficulties that confronting L2 learners. The focus of the current study is to investigate how L2 learners deal with divergence between the grammars of L1 and L2 and specifically, how English learners of Arabic deal with the wide range of dative structures, compared to their L1 dative structures. An example of the challenge facing them is the acquisition of the Scrambled Dative (SD) structures in Arabic. There is a disparity between Arabic and English in the allowance of a variety of dative word orders. Arabic allows the SD constructions, as presented in (1): 
(1) a. باعَ عمرُ لفاطمةَ القلمَ

$\begin{array}{lllll}\text { ba'a } & \text { omar-u } & \text { li } & \text { fatimat-a } & \text { alqalam-a } \\ \text { sold } & \text { Omar-Nom } & \text { prep } & \text { Fatimah-Gen } & \text { the pen-Acc }\end{array}$

'Omar sold to Fatimah the pen.'

b. باعَ عمرُ القلمَ فاطمةً

ba'a omar-u

alqalam-a fatimat-a

Sold Omar-Nom

the pen-Acc Fatimah-Acc

'Omar sold the pen Fatimah.'

English, on the other hand, has a fixed word order, which means that the SD structures are grammatically unacceptable, as illustrated in (2):

(2) a. *Ray sold to Peter the book.

b. *Ray sold the book Peter.

2. A comparative analysis of the syntactic features of dative structures in Arabic and English

\subsection{The syntactic features of dative structures in English}

In the English Prepositional Dative (PD) construction, the Noun Phrase (NP) must precede the Prepositional Phrase (PP), as shown in (3). Also, in the English Double Objective Dative (DOD) construction, both the Goal argument and the Theme argument have accusative case, since the Goal argument occupies the closest position to the functional head $v$, whereas the Theme argument is assigned inherent accusative case (Radford 2009: 407-8); however, the Goal argument should be followed by the Theme argument, as illustrated in (4):
Examples (1) and (2) present a challenge which probably faces English learners of Arabic to acquire the SD constructions, due to their ungrammaticality in L1. This illustration provides an example of the difficulty for English learners of Arabic in noticing the grammaticality of this structure in the L2.

This article is organised as follows. In section 2, a comparative analysis of the syntactic features of dative structures in English and Arabic is presented. Section 3 is an overview of SL hypothesis under examination, as well as previous acquisition studies of the dative alternation. Section 4 is a discussion of main research questions and predictions. The following section presents the experimental study, and the sixth section presents the analysis of the results, followed by a discussion of the results and conclusion. 
(3) a. Ian gave the pen to Dunstan.

b.

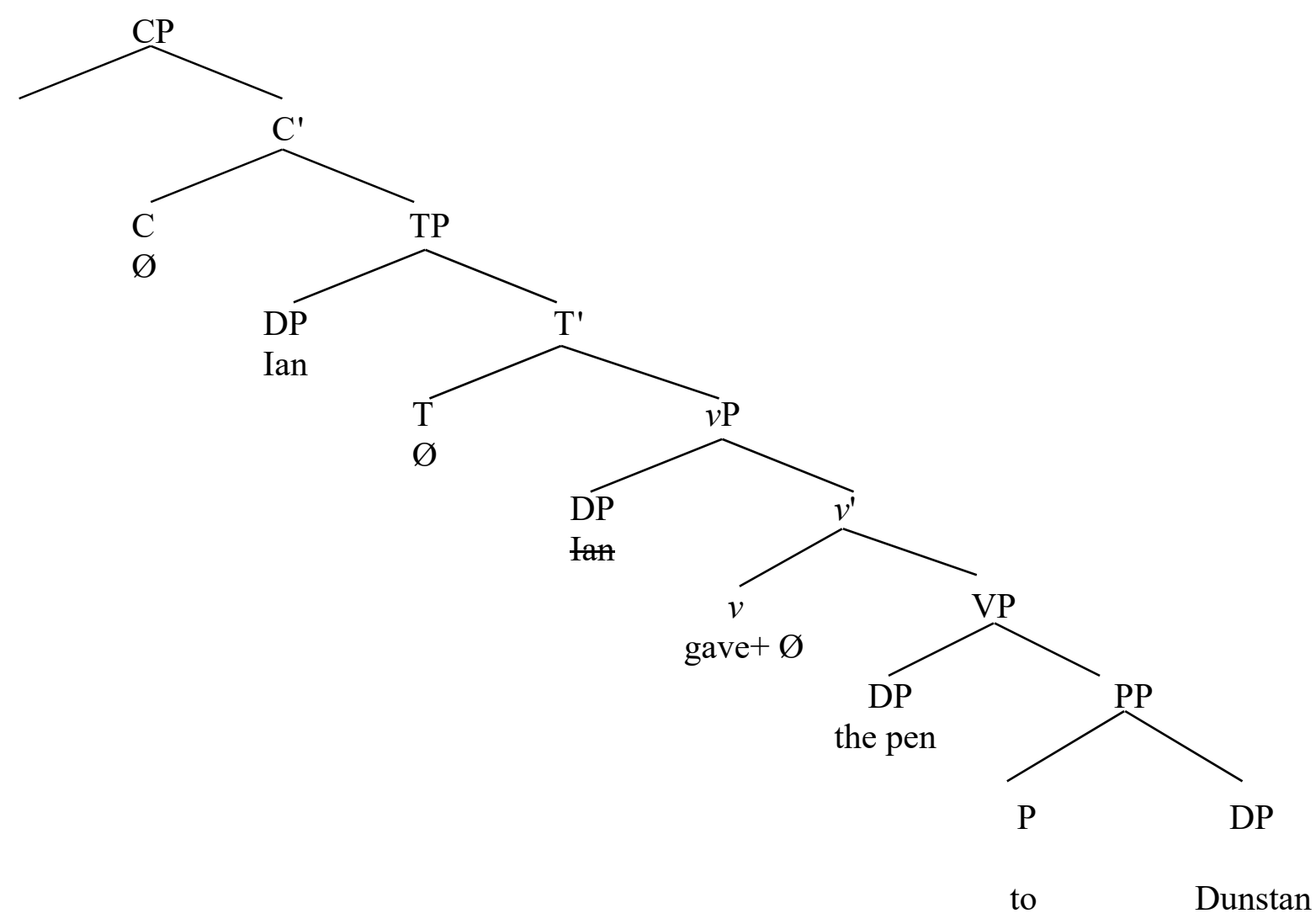


(4) a. Ian gave Dunstan the pen.

b.

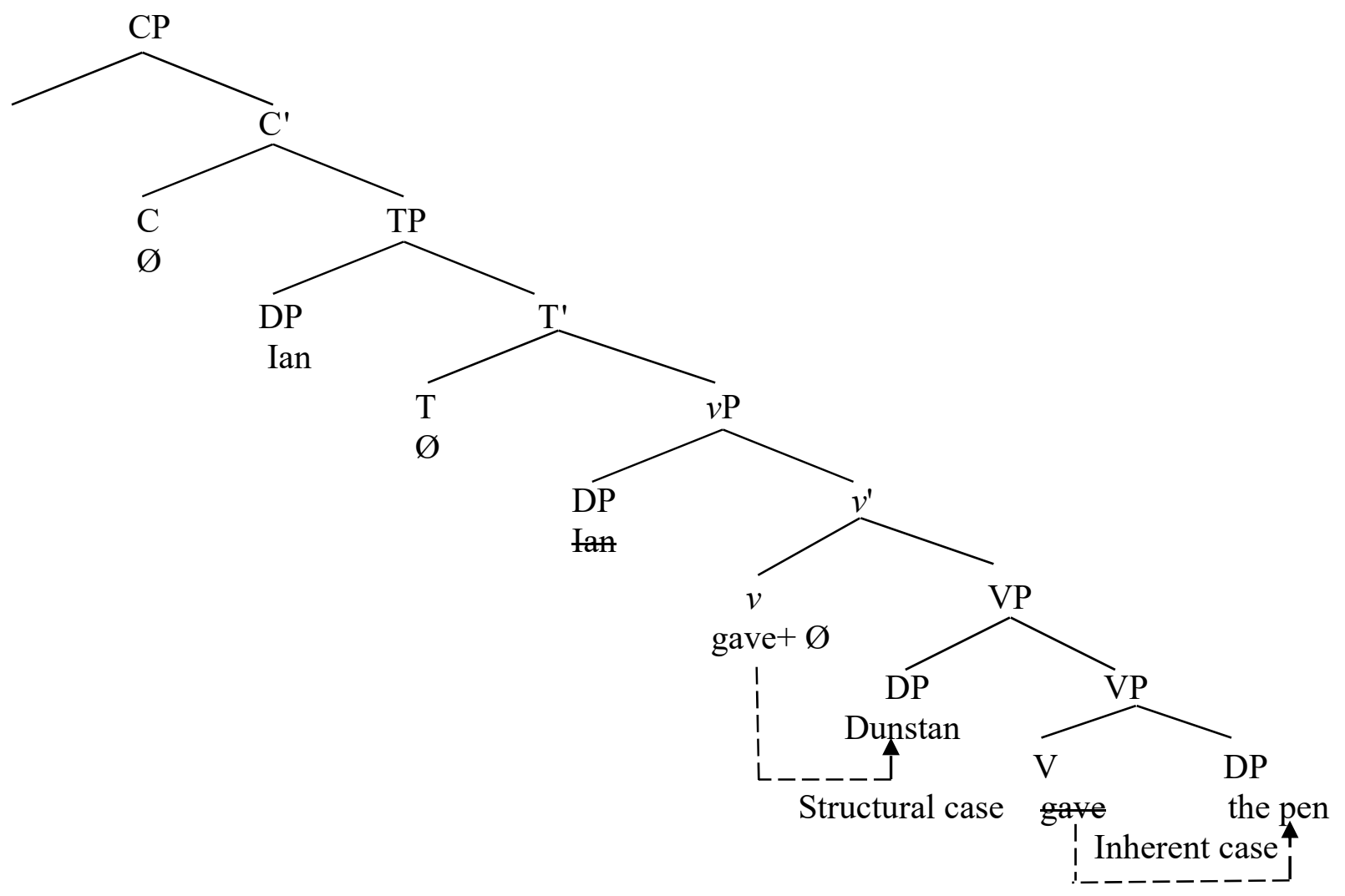

Therefore, English has a fixed word order, which means that, unlike Arabic, English does not allow SD constructions as in (5):

(5) a. *Sue gave to Ben the pencil.

b. * Sue gave the pencil Ben.

\subsection{The syntactic features of dative structures in Arabic}

A variety of Arabic verbs permit what is known as the dative alternation, as shown in the pair of sentences in (6). Example (6a) shows the Arabic PD structure and example (6b) illustrates the Arabic DOD structure. Dative verbs in Arabic are those which appear with two objects that cannot form a separate verb-less sentence by themselves. This definition was built on the base of the relationship between the two internal arguments of the dative sentence. In other words, the relationship between the indirect object (the Goal argument) such as 'Ali' in example (6b) and the direct object (the Theme argument) such as 'the book' in example (6b) does not have to be like the relationship between the subject and its complement in case of a verbless sentence. 
(6) a. a أعطى عمرُ الكتابَ إلى علي a

a'ta omar-u

gave Omar-Nom

'Omar gave the book to Ali.'

b. أعطى عمر عليًا الكتابَ

a'ta omar-u

gave Omar-Nom

'Omar gave Ali the book.'

To show the structures of the PD as in (6a) and the DOD as in (6b), I will assume that the direct and indirect objects are base generated inside the VP projection; the former occupies an intermediate position of VP, while the latter occupies the complement of the VP. This can be supported by the VP-Internal Subject Hypothesis, which is formulated by Koopman \& Sportiche (1988). They assumed that the subject of the simple clause is generated in the specifier of the VP, whereas the objects are generated inside the VP. Therefore, in the PD structure as in (6a), the direct object 'the book' adjoins to $\mathrm{V}$ ' and the
(Goal)

ela ali-in

prep Ali-Gen

(Theme)

alkitaab-a

the book-Acc

indirect object 'to Mohammed' has its own PP projection below the V. Similarly, the DOD structure as in (6b) has the indirect object 'Mohammed' adjoining the $\mathrm{V}$ ' and the direct object 'the book' is in the lowest position of the clause structure. The verb merges in the $\mathrm{V}$ and then moves to the $\mathrm{T}$ position via the $v$, while the subject merges in the spec-VP and moves to the spec- $v \mathrm{P}$ to receive the nominative case with the $\mathrm{T}$ 'gave', as shown in structure (7a \& $7 \mathrm{~b})$ :

(7) a. The tree of the Arabic PD structure

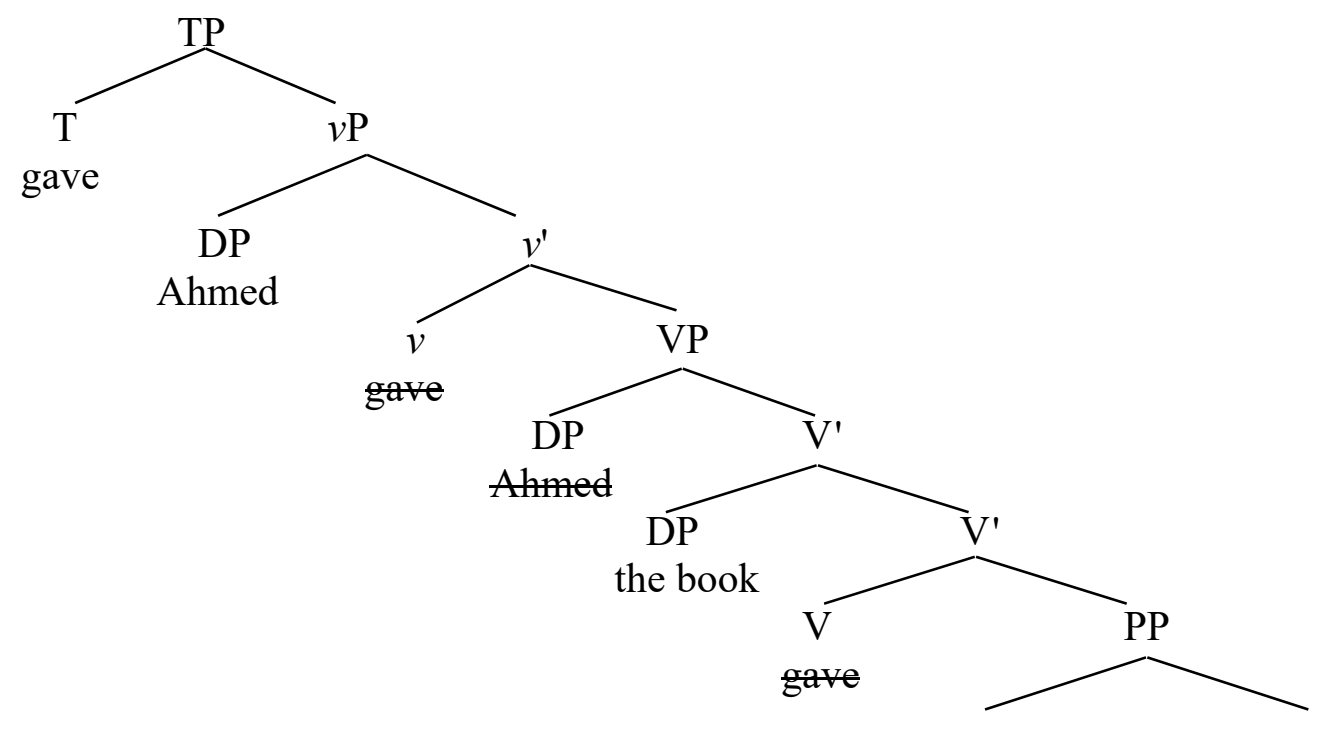




\section{$\mathrm{P}$}

DP

to

Mohammed

b. The tree of the Arabic DOD structure

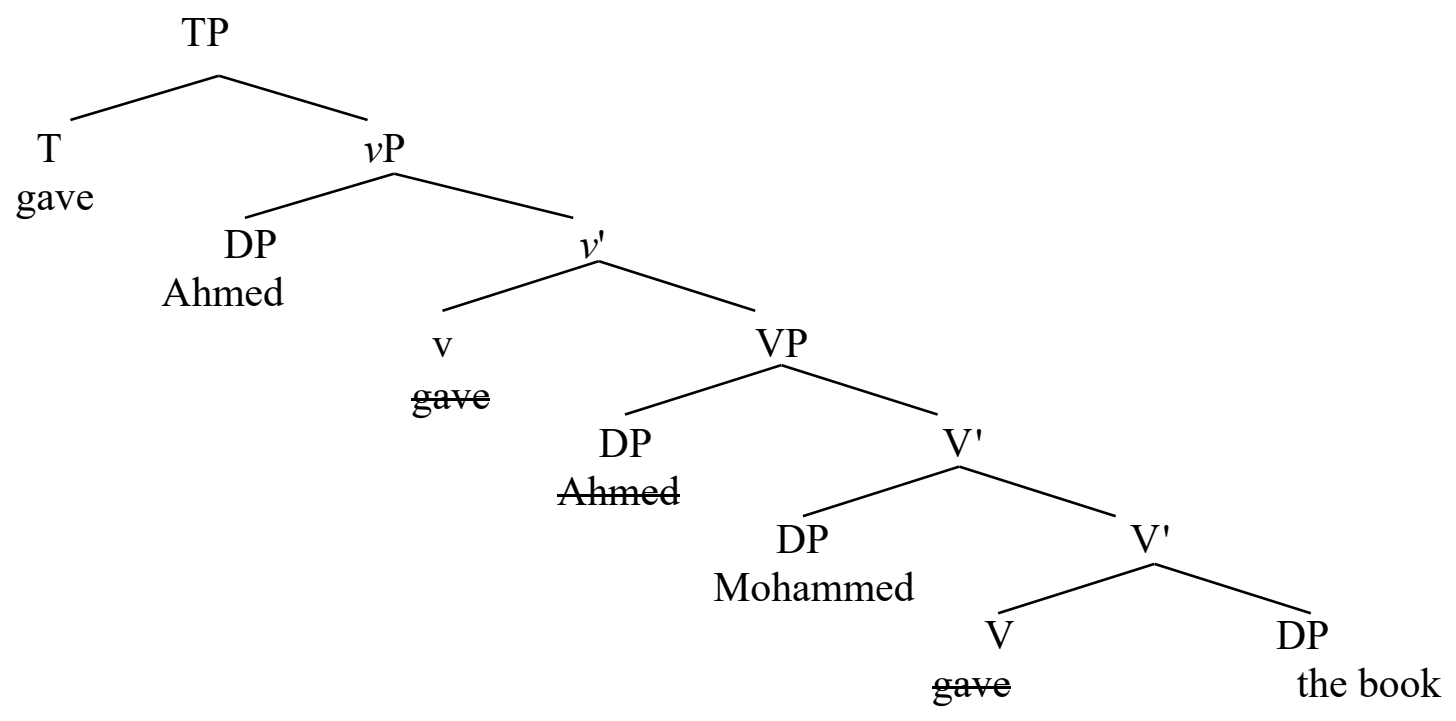

The Arabic DOD structure's arguments and the Theme argument in the PD structure are marked by the accusative case. However, the Goal argument in the PD structure is marked by the genitive case, since it is prefixed by benefactive/allative preposition ela 'to'. Therefore, the final case marker can be a fundamental element in allowing Arabic to have a great deal of freedom between the two internal arguments: the Goal and the Theme. This means that SD constructions are grammatically well-formed. Numerous Arabic grammarians, for instance, Sibawayh

(8)

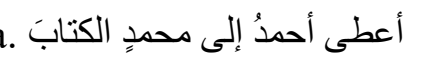

a'ta ahmed-u ela

gave Ahmed-Nom prep
(Goal)

(1988), Ibn S-Saraaj (1996), Hassan (1974) and Al-Oqaili (1985) have argued that the Goal/Theme order in (6) is the basic, and the Theme/Goal order, as illustrated in (8) is derived by scrambling. Thus, the examples in (6) show what are called the basic structures and the examples in (8) illustrate those referred to as the scrambling structures. These grammarians also argued that the scrambling structure is not as widespread as the basic structure.

(Theme)

'Ahmed gave the book to Mohammed.'

b. أعطى أحمدُ الكتاب محمدًا (Theme)

a'ta ahmed-u alkitaab-a

mohammed-in alkitaab-a

Mohammed-Gen the book-Acc

(Goal)

mohammed-an 
gave Ahmed-Nom the book-Acc Mohammed-Acc

'Ahmed gave the book Mohammed.'

The indirect object 'to Mohammed' in the SPD as in (8a) as well as the direct object in the SDOD 'the book' as in ( $8 b)$, must raise and land in a position higher than the direct object 'the book' and the indirect object 'Mohammed' respectively. Meanwhile, the subject which is in spc- $v \mathrm{P}$ should be higher than both the moved objects. Therefore, the indirect object in the SPD structure as in (8a) and the direct object in the SDOD structure as (8b) move to the edge of $v \mathrm{P}$, while the subject adjoins the out edge of the $v \mathrm{P}$. The fronted movement of the objects is motivated by the edge feature in $v$ heads of the $v \mathrm{P}$ phase (Chomsky 2005). He proposed that phase heads $\mathrm{C}$ and $v$ are endowed with the Edge feature $(\mathrm{EF})$ which requires $\mathrm{C}, v$ to attract elements to their edge $\mathrm{CP}, v \mathrm{P}$ as he applied it to the movement of the $w h$-phrase to spec-CP by the EF of the head C. Examples ( $9 a \& 9 b)$ show the diagrams of the SD structures:

(9) a. The tree of the Arabic SPD structure

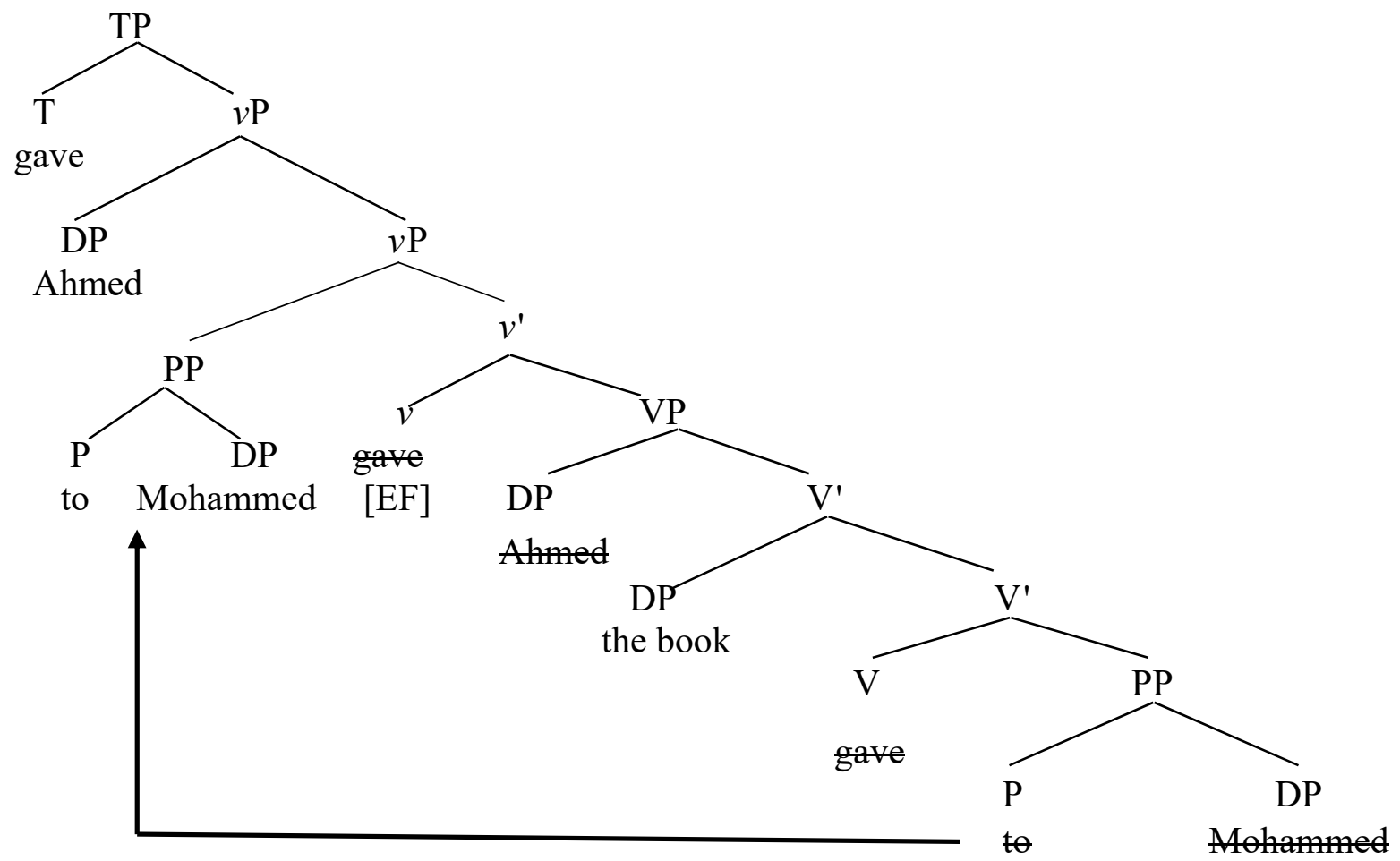


b. The tree of the Arabic SDOD structure

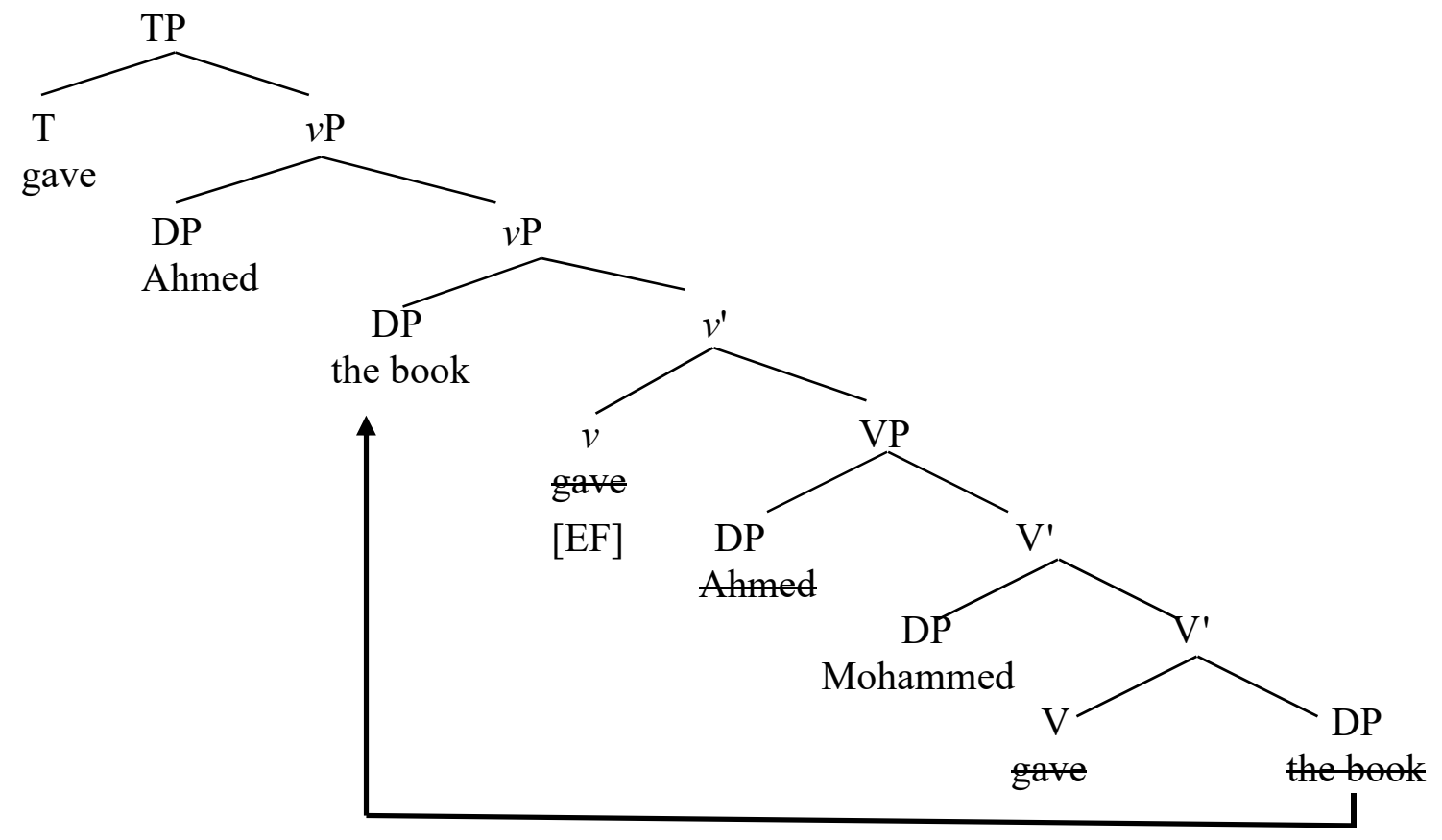

However, what is obvious with regard to SD structures is that non-alternating verbs such as the equivalent of 'kick' are not allowed to occur in the SDOD structure, but are permissible in the SPD construction, as in the following example:

$$
\begin{array}{ll}
\text { a. ركلَ أحمدُ إلى محمدِ الكرةً } & \text { ahmed-u } \\
\text { rakala } & \text { ahmed-Nom } \\
\text { kicked } & \text { Ahmed }
\end{array}
$$

(Theme)

$$
\begin{array}{lll}
\text { ela } & \text { Mohammed-in } & \text { alkorat-a } \\
\text { prep } & \text { Mohammed-Gen } & \text { the ball-Acc }
\end{array}
$$

'Ahmed kicked the ball to Mohammed.'

b.

$$
\begin{array}{cl}
\text { *rakala } & \text { ahmed-u } \\
\text { kicked } & \text { Ahmed-Nom }
\end{array}
$$

(Theme)

alkorat-a

the ball-Acc

\section{(Goal)}

mohammed-a

Mohammed-Acc

'Ahmed kicked the ball Mohammed.'

\section{L2 acquisition theories}

This section intends to shed light on the Full Transfer and Full Access (FT/FA) approach, as well as the Feature Reassembly
Hypothesis (FRH), proposed by Lardiere (2008, 2009, 2013), followed by certain related studies investigating the acquisition of dative constructions in L2 contexts. 
The FT/FA approach, formulated by Schwartz and Sprouse (1994, 1996), states that the initial stage of the acquisition of L2 is the final stage of the L1 grammar and L2 learners will transfer the L1 representations to the L2 grammar (FT). This means that the initial stage of L2 is divergent from the initial stage of L1. Later, L2 learners will have to restructure their interlanguage and resort to principles and operation constrained by $\mathrm{UG}$, once the input cannot be analysed by the L1 grammar (FA). In certain circumstances, the restructuring will occur possibly rapidly, while in other circumstances, much more time may possibly be required. The course that L2 development takes is partly determined by the initial state, input, UG and learnability considerations.

The FRH argues that successful L2 acquisition proceeds by means of reassembling sets of lexical features drawn from the L1 lexicon into feature bundles appropriate to $\mathrm{L} 2$. The feature reassembly process follows 'initial mapping' as argued by Gil and Marsden (2013:118):

'L2 acquisition proceeds by means of the learner perceiving correspondences between lexical items in the L2 input and items in their own L1. This results in the L2 form being mapped to the L1 feature set for the item that is perceived to be equivalent. Once this initial mapping is established, 'feature reassembly' can occur, if required: features can be added or deleted from the L1-based feature set, as motivated by evidence in the input.'

The FRH follows the FT/FA approach by assuming that adult L2 learners bring the formal features, which are assembled into the L1 lexical items to the task of L2 acquisition. It could be said that the FRH is a modulation of the FT/FA approach, as it insists that the successful acquisition of L2 relies on reassembling the sets of feature bundles of
L1 lexical items into feature bundles appropriate to the L2, in circumstances where divergences occur.

The learning task for L2 learners is twofold: mapping features and feature reassembly. Firstly, L2 learners have to map a lexical item to its closet equivalent in L2, then, they reassemble the features that do not correspond within both L1 and L2. During the first stage, which is the mapping of the sets of lexical items in L1 to those of L2, Lardiere (2009:191) remarked,

'It seems plausible to assume (and the feature re-assembly approach indeed rests on the assumption) that learners will look for morpholexical correspondences in the L2 to those in their L1, presumably on the basis of semantic meaning or grammatical function (the phonetic matrices will obviously differ).' Consequently, the FRH assumes that L1 transfer is the initial attempt to directly map between L1 and L2 lexical items. However, in the case of failure of mapping, L2 learners need to refine the combined features which were transferred from their L1 and reassemble features that are attributed to different feature bundles in L1 and L2.

At the second stage which is feature reassembly, L2 learners may need either to learn new features, or abandon features allowed in their L1, but not in their L2. As a consequence, interlanguage development might be conceptualised by the FRH as a process of incorporating $\mathrm{L} 1$ features into those of L2 .

\section{Previous studies investigating the acquisition of the dative alternation} Under this umbrella, certain previous studies examining the acquisition of the dative alternation, where the L1 grammar is wider than its counterpart in the L2, are reviewed. One of the earliest studies was carried out by Mazurkewich (1984) who investigated how French learners of English acquire the dative 
alternation. English presents a wider range of dative structures as it allows both the PD DOD structures, whereas French allows only the PD structure. She found that French learners of English accepted the DOD structure despite its absence in their L1, as they became more proficient in English, supporting the view that L2 learners would be able to realise the grammaticality of structures not allowed in their L1.

In a series of studies, Le Compagnon (1984) investigated the extent of L1 influence on the acquisition of the English dative alternation by native speakers of French. The data were collected from two case studies as well as two judgment tests done by four French native speakers. It was expected that French learners of English would accept the PD structure based on the L1 knowledge and the positive evidence and would be categorised as an unmarked structure. However, an example such as I gave the book to you, which shows the indirect object pronoun in the PD structure, would be expected to be ungrammatical. On the other hand, the DOD structure will be categorised as a marked structure and will not be acquired without positive evidence. However, the DOD structure with indirect object pronoun as $I$ gave you the pen would be expected to be judged as a grammatical sentence, since the indirect object follows the verb. Generally, the results showed that the DOD structure was accepted as a grammatical structure with a pronoun indirect object. Moreover, the PD structure was accepted as grammatical with the noun indirect object. The overgeneralisation made by these L2 learners is due to the wrong assumption concerning marked and unmarked structures in English, for which there is positive evidence in both L1 and L2. These results were interpreted as evidence of the influence of the grammatical structure of L1 on the acquisition of L2.
A further study was carried out by Kang (2008), who investigated the acquisition of the English dative alternation by Korean EFL children. English is close to an isolating language where the DOD structure is assigned by a word order, which means that English has a fixed word order and the SD structures are impossible in English. On the other hand, Korean is an agglutinative language, where most words including the arguments of the dative verbs are assigned by adding a morpheme. The morphemes are more important than the word order. This means that the SD structures are possible in Korean. Regarding language typology and L1-transfer, it was predicted that Korean EFL children would acquire the PD structure earlier than the DOD structure, as well as transfer the SD structures into English. It was found that Korean EFL children not only acquired the PD structure earlier than the DOD structure, but also transferred the SD structure into English.

Anderssen et al. (2014) looked at the acquisition of the Norwegian dative alternation by Norwegian children. They explored the pragmatic principle (given-ness) which led the native speakers of Norwegian syntactically to choose one word order over another. They found that children preferred the PD structure to the DOD structure as the basic word order, in various discourse contexts. They (2014: 72) suggested that:

'Children's behaviour is not a result of a pragmatic deficit or an immature syntactic component per se but rather a failure to consistently integrate the two.'

De Cuypere et al (2014) reported an investigation of the acquisition of the English dative alternation by Russian native speakers. An acceptability judgement test was conducted to investigate the choice of one dative structure before the other. A subtle preference for the use of the PD structure was revealed and this was attributed to the 
language acquisition process as suggested by the Processability Theory (PT), which implies that constructions which are easiest to process will be learned earlier than constructions which are harder to process, despite the convergences between the L1 and the L2.

Jäschke and Plag (2016) examined the acquisition of the English dative alternation by native speakers of German. They intended to investigate the preference of the dative structures, the PD or the DOD in English by advanced German native speakers. They also investigated the extent to which German learners' preferences are affected by the same constraints as assumed to affect L1 learners' preferences. It was revealed that the PD construction was slightly preferred by the participants. They argued that L2 learners are effected by the same factors, as for instance, animacy of the recipient, pronominality of the theme and definiteness of recipient as L1 learners, but to a lesser degree. The results suggested that L2 learners initially do not make use of probabilistic constraints, despite the constraints being effective in the L1 and only gradually learn a sensitivity of the constraints that govern the preference of the two structures.

\begin{tabular}{lll}
\multicolumn{2}{r}{ a. أعطى أحمدُ إلى محمدٍ الكتابَ } & \\
a'ta & ahmed-u & ela \\
gave & Ahmed-Nom & prep
\end{tabular}

'Ahmed gave the book to Mohammed.'

b. ركل أحمدُ إلى محمدٍ الكرة

rakala ahmed-u ela

kicked Ahmed-Nom prep

'Ahmed kicked the ball to Mohammed.'

c. أعطى أحمدُ الكتاب محمدًا

$\begin{array}{llll}\text { a'ła } & \text { ahmed-u } & \text { alkitaab-a } & \text { mohammed-an } \\ \text { gave } & \text { Ahmed-Nom } & \text { the book-Acc } & \text { Mohammed-Acc }\end{array}$

\section{Research questions}

Due to the cross-linguistic disparities existing between Arabic and English, the researcher endeavored to explore whether or not English learners of Arabic at different proficiency levels show acquisition of the SD structures in the target language. It is assumed that with an increase in the proficiency level of English learners, there will be a corresponding increase in their acquisition of the Arabic SD structures. Consequently, it is expected that pre-intermediate learners may face difficulties in acquiring structures that are not allowed in their L1 grammar, as they are not exposed enough to the required positive evidence to arrive at the L2 grammar. However, upper-intermediate learners may acquire properties that are not allowed in the L1 due to the availability of positive evidence. To explore these expectations, the current study proposes to investigate whether these L2 learners can realise the grammaticality of the SD structures in Arabic as in the following examples:

mohammed-in alkitaab-a

Mohammed-Gen the book-Acc

mohammed-in alkorat-a

Mohammed-Gen the ball-Acc

'Ahmed gave Mohammed the book.' 


\section{The current empirical study}

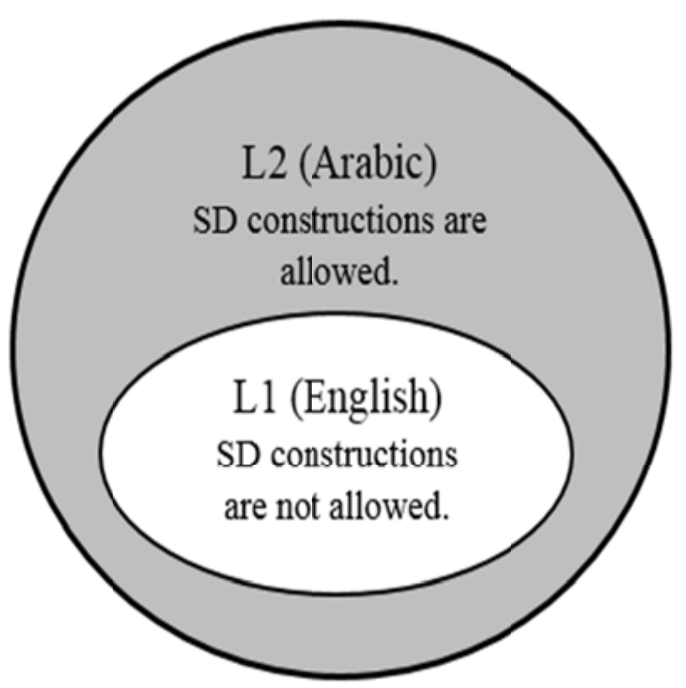

glish)

This study explores how well L2 learners are capable of realising the extent of L2 argument structures compared to their L1. It investigates the acquisition of the SD structures in Arabic by native speakers of English, since all the SD structures are permitted in Arabic, but not in English, as shown in Figure 1.

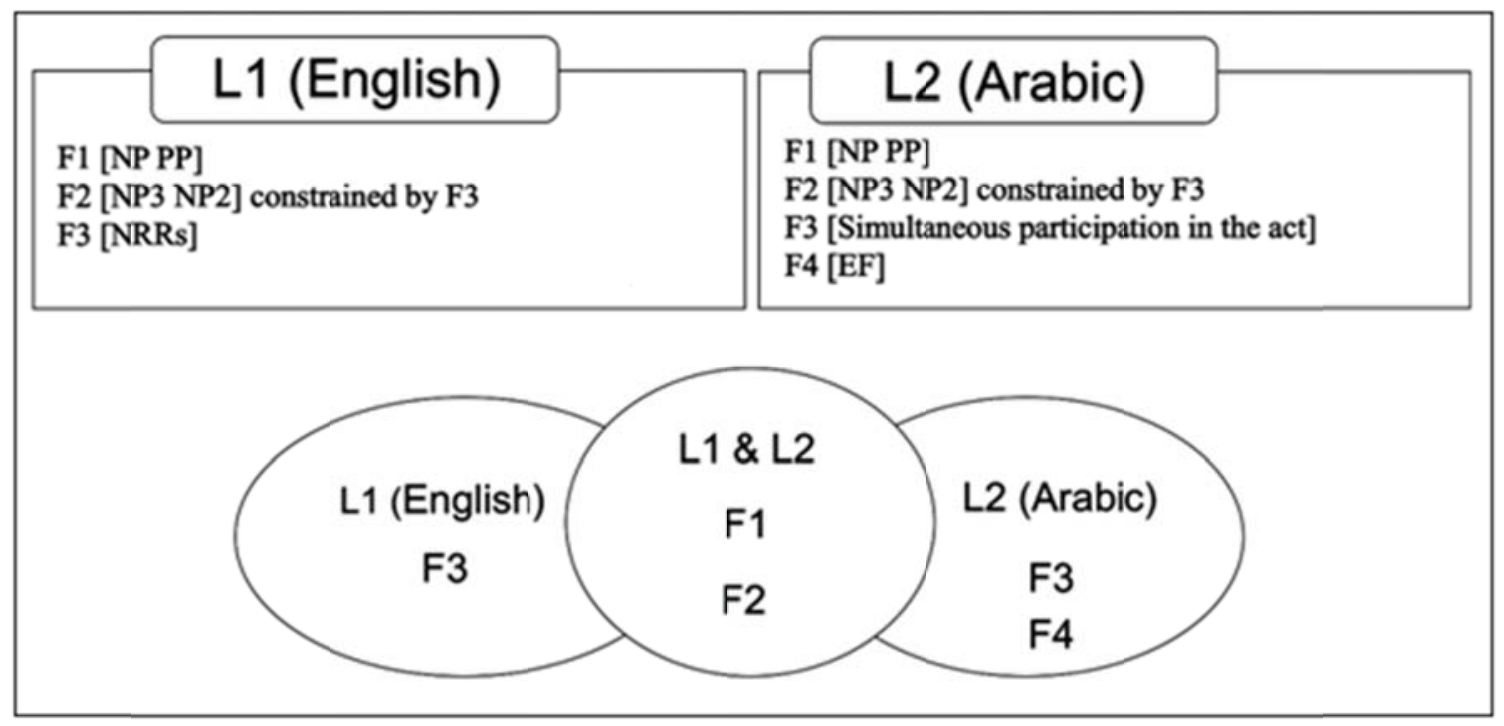

An important question that may arise is: how can L2 learners of Arabic acquire the SD structures. According to the superset and the subset of English and Arabic dative features as illustrated in Figure 10, English learners of Arabic have a twofold task to be achieved, to acquire their L2 grammar. First, they have to map their L1 grammar to the equivalents in 
the L2 grammar, i.e., they should map the PD structure with all dative verbs and the DOD structure with some verbs like 'give', 'tell' and 'show', as they are available in both the languages. Second, they need to reassemble features that are not available in their L1 based on the positive evidence such as the EF that allows the lower object move to a higher position. Learning such a syntactic feature based on the positive evidence may facilitate them in acquiring the SD structures. Overall, they should receive positive evidence to realise the superset of their L2.

\section{Research Methodology}

\subsection{Participants}

The sample of this study consisted of two groups, the Arabic group who acted as controls with 10 native speakers of Arabic and the English learners acquiring Arabic, who acted as experimental participants. A total of 40 English-speaking learners of Arabic was involved, 20 learners at the preintermediate level and the rest at upperintermediate level.

\subsection{Design and Material}

The target items were composed of 12 verbs expressed in two different structures. These 12 verbs were $a^{\prime} t a$ 'give ', $b a^{\prime} a$ 'sell', dafa'a 'pay', nawala 'hand', akbara 'tell', qara 'read', kataba 'write', araa 'show', rama 'throw', rakala 'kick', qażafa 'toss' and saddada 'shoot'. A total of 24 sentences were investigated in this study. Each pair of sentences presented an investigated verb. The sentences were presented with a picture and followed by a three-point Likert scale from 1 (bad example) through 2 (not sure) to 3 (good example). $a$ ' $t a$ 'give 'is taken as an example, as illustrated in Table 1.

\begin{tabular}{|c|c|c|}
\hline The abbreviation of each structure & language & Example \\
\hline \multirow{2}{*}{ SPD1 } & Arabic & باعَ سالمُّ لأحمدَ السيارةً. \\
\hline & English & Salem sold to Ahmed the car. \\
\hline \multirow{2}{*}{ SDOD1 } & Arabic & أعطى أنورُ الكتابَ مجدى. \\
\hline & English & Anwar gave the book Majdi. \\
\hline \multirow{2}{*}{ SPD2 } & Arabic & دفعَ هاني لسمرَ عشرةُ دراهٍٍِ. \\
\hline & English & Hani paid to Samar ten pounds. \\
\hline \multirow{2}{*}{ SDOD2 } & Arabic & رمى فايزّ القلمَ فوازًا. \\
\hline & English & Fayez threw the pen Fawaz. \\
\hline
\end{tabular}

\subsection{Data analysis}

The experimental participants were classified into two groups: pre-intermediate level and upper-intermediate level.

The picture judgment task was divided into three groups of participants: native speakers, upper-intermediate learners and preintermediate learners. Then, the data were analysed in two stages. In the first stage, the data were entered into SPSS (version 21.0) to attain the means. The data were organised in the following way to attain the means. The verbs used in the study were classified into 
two classes. The first class comprised of five alternating Arabic verbs ('give', 'sell', 'hand', 'tell' and 'show'). The second class included seven non-alternating Arabic verbs ('pay', 'read', 'write', 'throw', 'kick', 'toss' and 'shoot'). These two classes come with two different structures: SPD structure and SDOD structure. As a result of this classification, the study has four categories: SPD1 structure ('give', 'sell', 'hand', 'tell' and 'show'), SDOD1 structure ('give', 'sell', 'hand', 'tell' and 'show'), SPD2 structure ('pay', 'read', 'write', 'throw', 'kick', 'toss' and 'shoot') and SDOD2 structure ('pay', 'read', 'write', 'throw', 'kick', 'toss' and 'shoot'). The first category was taken to demonstrate how the means were obtained. Each participant's

\section{Results}

Figure 3 . The mean responses on the acquisition of the Arabic scrambling constructions

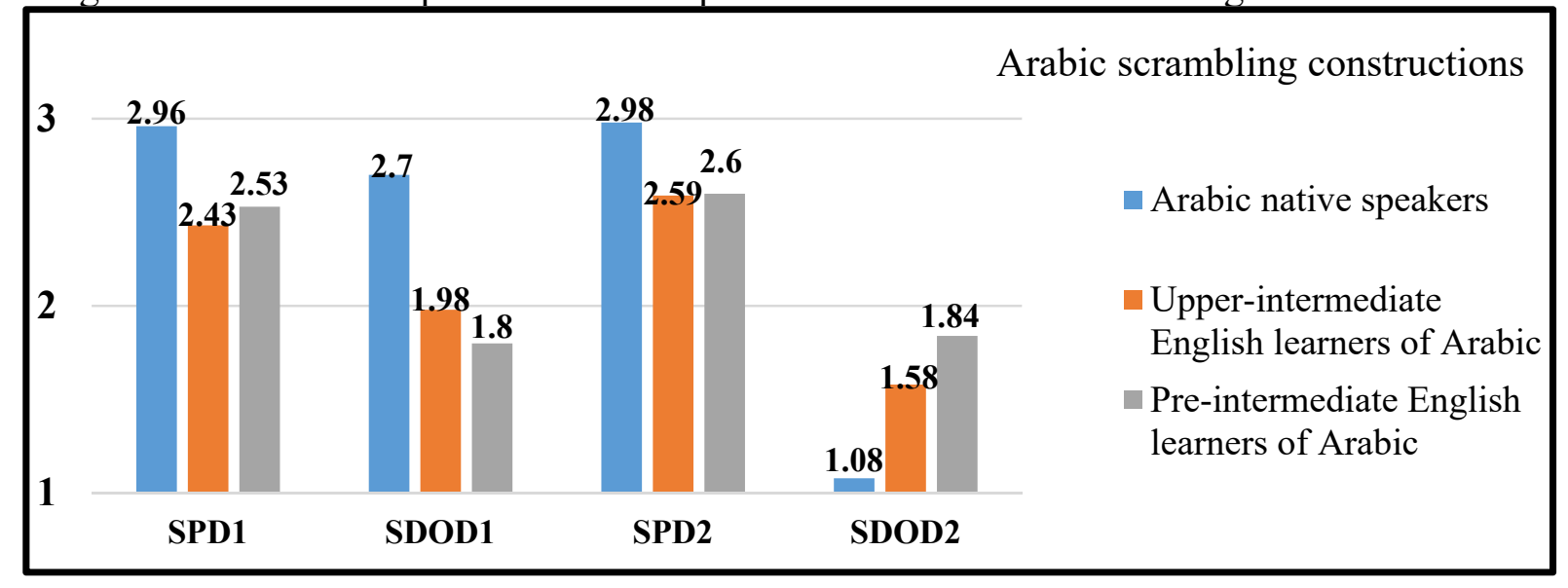

\begin{tabular}{|c|c|c|c|c|}
\hline \multicolumn{5}{|c|}{ Table 2. Tests of within-subjects effects on Arabic scrambling structures } \\
\hline Source & DF & MS & F & Sig. \\
\hline Structures & 1 & 11.530 & 69.863 & .000 \\
\hline Structures * group & 2 & 1.202 & 7.281 & .002 \\
\hline Verb group & 1 & 7.200 & 101.876 & .000 \\
\hline Verb group * group & 2 & 1.275 & 18.043 & .000 \\
\hline Structures * verb group & 1 & 15.995 & 182.413 & .000 \\
\hline Structures * verb group * group & 2 & 1.080 & 12.318 & .000 \\
\hline
\end{tabular}

A three-way ANOVA repeated measure, which was run among participant groups response was summed up and divided by five, since this group contains five verbs. After that participants' means were summed up and divided by their total number to obtain the mean values.

In the second stage, the statistical analysis was built on value means of each structure. The comparison between the participants' groups was based on three-way ANOVA repeated measures followed by the t-test, to determine whether the means of the participant groups were statistically different from one another. Finally, the charts and tables were prepared in an Excel file, providing the reader with a wide view of the participants' responses. 
learners of Arabic), within structures (SPD vs. SDOD) and verb groups (group one \{give, sell, hand, tell and show $\}$ vs. group two \{pay, read, write, throw, kick, toss and shoot\}) as within-subject variables, showed all variables revealing significant disparities, as illustrated in Table 2. The interaction between structures, verb group and group also revealed a significant difference $F(17.759)=2.149, p$
$=.000$. However, the interaction between structure and group showed no significant disparity $\mathrm{F}(1.037)=.470, \mathrm{p}=.362$. Two-way ANOVA analysis should be run to realise the disparity level of each variable. Table 3 illustrates the statistical analysis of the Arabic SPD1 and SDOD1 structures

Table 3. Tests of within-subjects effects on the Arabic SPD1 and SDOD1 structures

\begin{tabular}{|c|c|c|c|c|}
\hline Source & DF & MS & F & Sig. \\
\hline Structures & 1 & 5.184 & 22.054 & .000 \\
\hline Structures * group & 2 & .414 & 1.760 & .183 \\
\hline
\end{tabular}

Table 3 compares participant groups (native speakers of Arabic, upper-intermediate learners and pre-intermediate learners of Arabic), within structures (SPD1 vs. SDOD1) as within-subject variables. No disparity was found within the combination of structures and group $\mathrm{F}(1.760)=.414, \mathrm{p}=.138$, as illustrated in Table 3. Therefore, there is no interaction between group and structure to analyse any further. Turning to the statistical exploration of the Arabic SPD2 and SDOD2 structures, Table 4 shows the analysis of the investigation of the Arabic SPD2 and SDOD2 structures.

Table 4. Tests of within-subjects effects on Arabic SPD2 and SDOD2 structures

\begin{tabular}{|c|c|c|c|c|}
\hline Source & DF & MS & F & Sig. \\
\hline Structures & 1 & 33.698 & 99.395 & .000 \\
\hline Structures * group & 2 & 2.205 & 6.504 & .003 \\
\hline
\end{tabular}

An additional two-way ANOVA, which compares participant groups (native speakers of Arabic, upper-intermediate learners and pre-intermediate learners of Arabic), within structures (SPD2 vs. SDOD2), showed a significant disparity not only with structures $\mathrm{F}$ $(99.395)=33.698, \mathrm{p}=.000$, but also within the interaction between structures and group $\mathrm{F}$ $(6.504)=2.205, p=.003$, as revealed in Table
5. These divergences need to be further explored by one-way ANOVA to realise the value of the interaction. 
Table 5. One-way ANOVA on Arabic SPD2 and SDOD2 structures

\begin{tabular}{|c|c|c|c|c|}
\hline Source & DF & MS & F & Sig. \\
\hline SPD2 & 2 & .596 & 2.387 & .103 \\
\hline SDOD2 & 2 & 1.911 & 6.608 & .003 \\
\hline
\end{tabular}

As shown in Table 5, there is no significant disparity between the participants on the assessment of the SPD2, F (2.387) $=.596, \mathrm{p}=$ .103. Nevertheless, a significant difference was found in the assessment of the SDOD2 structure, $\mathrm{F}(6.608)=1.911, \mathrm{p}=.003$. The assessment of the SDOD2 structure ought to be further investigated by t-test to identify the significant result. The following two tables show the comparison between the native speakers and the non-native speakers' -ntin It is obvious that there is a sig 343 variation between the native speakers group and the experimental groups in the judgement of the SDOD2 structure, as shown respectively in Table 6 and Table 7.

\begin{tabular}{|c|c|c|c|c|}
\hline Groups of participant & $\mathrm{N}$ & Structure & Mean & Sig. \\
\hline Arabic native speakers & 10 & \multirow{2}{*}{ SDOD2 } & 1.08 & \multirow{2}{*}{.014} \\
\hline Upper-intermediate English learners of Arabic & 20 & & 1.58 & \\
\hline
\end{tabular}

Table 7. Comparison between Arabic native speakers and pre-intermediate English learners of
Arabic assessing the SDOD2 structure in Arabic
\begin{tabular}{|l|c|c|c|c|}
\hline Groups of participants & $\mathrm{N}$ & Structure & Means & Sig. \\
\hline Arabic native speakers & 10 & SDOD2 & 1.08 & \multirow{2}{*}{.000} \\
\cline { 1 - 1 } & & & 1.84 & \\
\hline
\end{tabular}

To conclude, the statistical investigations showed that the participants varied significantly on the assessments of the SDOD2 structure due to the disparity between the participants' L1 and L2.

\section{Discussion of the results}

It was anticipated that the L2 Arabic learners will acquire the SDOD1 structure, especially those at the upper-intermediate level, owing to the availability of positive evidence. It was also predicted that the upper-intermediate participants would perform better than the 
pre-intermediate participants, due to their high proficiency level in L2 grammar.

According to this empirical data, it was revealed that English learners at the upperintermediate level did accept the Arabic SDOD1 structure as good in Arabic. Their ratings were lower than those of the native speakers (2.70 vs.1.98). Further, those who were at the pre-intermediate level statistically could not realise the grammaticality of the SDOD1 structure. No significant disparity between the assessment of the experimental groups and the native speakers' assessment on this structure was revealed, as seen in Table 3. These results may be explained by the fact that these learners noticed the overlap between the L1 grammar (English) and the L2 grammar (Arabic) and assumed these languages to be the same to a great extent, if not identical. Consequently, the SDOD1 structure should be unacceptable in both English and Arabic. These findings support the hypothesis of this thesis, which was that the English learners of Arabic could acquire the SDOD1 structure even though such structure is not allowed in their L1. It could be a contribution to the FA approach as L2 learners accepted this structure despite its absence in their L1 grammar. These learners will gain a better understanding of the extension of the Arabic structures, once they possess a higher proficiency level and are exposed more to Arabic grammar. It might be suggested that these learners would be able to learn this structure, once sufficient positive evidence on such construction is available to them.
Moreover, it was found that the English learners of Arabic accepted the SPD structures. The findings showed no differences between the English participants. This finding was predictable and suggests that the participants had the ability to learn the SPD constructions which do not exist in their L1, since such constructions are found and available in the L2 input. These learners may then perceive the use of the SPD structures, assisting them to obtain a wide understanding of the Arabic representation. Although the English learners did not accept these structures as high as the native speakers of Arabic did. It is likely that the English learners of Arabic reach a higher rating for such structures, when they possess greater proficiency in their L2, owing to the increased exposure these learners will receive. The findings of the acquisition of the SPD structures in Arabic are in accord with the idea indicating that L2 learners can learn structures that do not exist in their L1.

The results of the acquisition of the SD structures seem to be consistent with some of the previous studies. An example of these studies is the one by Mazurkewich (1984), who found that French learners acquire the DOD structure in English despite its ungrammaticality in their L1.

It also supports the finding of Inagaki (2001), who investigated how Japanese learners at the intermediate level acquire the manner of motion verbs with PPs expressing a goal in English, with such a structure as John walked to school. The result showed that these learners acquired such a structure which is absent in their L1. 
What may seem from the interpretation of such a result when the L2 is a superset of L1 argument structures, is that positive evidence should usually be sufficient to assist L2 learners to broaden their inter-language grammar. Positive evidence must be consistent, frequent, and clear to L2 learners to appreciate and understand it accurately. It is likely that positive evidence can be clear, but not frequent, or very frequent, but not clear or misleading in its meaning. Consequently, positive evidence must be both clear and frequent, for it to be effective in assisting L2 learners to overcome the impact of the L1 and comprehend L2 grammar.

The key point to highlight here is that the English learners of Arabic ultimately recover from the issue of under-generalisation. White (1991) argued that it is easier to overcome the issue of under-generalisation in the acquisition of L2 argument structures, than the issue of over-generalisation. Initially, once the L2 learners assume a restrictive grammar, L2 positive evidence will probably draw their attention to the extension of L2 grammar. Once the English learners of Arabic at the pre-intermediate level perceive the grammaticality of sentences such as Ali gave the book Mohammed in Arabic, they will restructure their grammar to incorporate the Arabic SDOD1 structure, which is not allowed in their L1.

\section{Conclusion}

The current study attempts to investigate the extent to which English learners of Arabic are influenced by their L1 or can access L2 grammar and acquire structures that are not possible in their L1. This study examined the acquisition of SD structures in Arabic by English native speakers. Arabic (L2) allows the SD structures, whereas English (L1) does not.

Overall, the results showed that there is no significant disparity between the participants on the assessment of the Arabic SD structures. According the findings of this study, it can be claimed that the current L2 learners majoring at pre-intermediate and upper-intermediate levels seemed to acquire L2 structures, even though such structures are not possible in their L1. The findings could be interpreted to say that L2 learners would acquire L2 syntactic configurations, once the input cannot be analysed by the L1 grammar.

\section{Bibliography}

Al-Oqaili, A. Sharh Ibn Aqeel, Damascus Dar al-Fikr.

Anderssen, M., Rodina, Y., Mykhaylyk, R. \& Fikkert, P. (2014). The acquisition of the dative alternation in Norwegian. Language Acquisition, 21, 72-102.

Chomsky, N. (2005). On Phases. Ms. MIT.

Compagnon, B. L. (1984). Interference and overgeneralization in second language learning: the acquisition of English dative verbs by native speakers of French. Language Learning, 34, 39-57.

De Cuypere, L., De Coster, E. \& Baten, K. (2014). The acquisition of the English dative alternation by Russian foreign language learners. PHRASIS (GENT): Studies in language and literature, 187212. 
Gil, K. H., \& Marsden, H.(2013). Existential quantifiers in second language acquisition:

A feature reassembly account. Linguistic Approaches to Bilingualism, 3(2), 117-

149.

Hassan, A. (1974). Al-Nahwu Al-Waafii, Cairo. Egypt Daar Al-Ma?aarif.

Ibn S-Saraaj, M. B. S. (1996). Al-Aušool fi AlNahwi, Beirut, Al-Resalah Publishers.

Inagaki, S. (2001). Motion verbs with goal PPs in the L2 acquisition of English and Japanese. Studies in Second Language Acquisition, 23, 153-170.

Jäschke, K. \& Plag, I. (2016). The Dative alternation in German-English Interlanguage. Studies in Second Language Acquisition, 38, 2016.

Kang, S. (2008). The acquisition of English dative constructions by Korean EFL children. In Proceedings of The 16th Conference of Pan-Pcific Association of Applied Linguistics, pp. 62-67.

Koopman, H. \& Sportiche, D. (1988). Subjects. Ms., UCLA, Los Angeles, California

Lardiere, D(2008). Feature assembly in second language acquisition. In: Liceras J, Zobl H and Goodluck, H. (eds) The role of formal features in second language acquisition. New York: Lawrence Erlbaum, 106-40.
Lardiere, D (2009). Some thoughts on the contrastive analysis of features in L2 acquisition. Second Language Research 25: 173-227.

Lardiere, D. (2013). Linguistic approaches to second language morphosyntax. In S. Gass \& A. Mackey (Eds.), The Routledge Handbook of Second Language Acquisition (pp. 106-126). Routledge.

Mazurkewich, I. (1984). The acquisition of the dative alternation by second language learners and linguistic theory. Language learning, 34, 91-108.

Radford, A. (2009). Analysing English sentences: A minimalist approach Cambridge University Press.

Schwartz, B. D. (1996). Now for some facts, with a focus on development and an explicit role for the L1. Behavioral and brain sciences, 19, 739-740.

Schwartz, B. D. \& Sprouse, R. (1994). Word order and nominative case in nonnative language acquisition: a longitudinal study of (L1 Turkish) German interlanguage. Language acquisition studies in generative grammar, 31, 71-89.

Sibawayh, A. B. O. Al-kitaab. Edited by Abdussalaam Haroon (1988), Cairo, Maktabat Al-khanagii.

White, L. (1991). Argument structure in second language acquisition. Journal of French Language Studies, 1, 189-207. 


\section{اكتساب التناوب بين مفعولي أعطى و أخو اتها من قبل متعلمي العربية كلغة ثانية أنور بن سعد الجدعاني

$$
\begin{aligned}
& \text { أستاذ مساعد في علم اللغة التطبيقي- قسم المواد العامة } \\
& \text { كلية الآداب والعلوم الإنسانية }
\end{aligned}
$$

مستخلص. هذه الدراسة التجريبية تناقش قدرة متعلمي اللغة الثانية في اكتساب تر اكيب اللغة الثانية الغير اللغوية في اللغة الأولى. شارلك في هذه الدر اسة أربعون طالبا إنجليزيا ممن يدرسون اللغة اللغة العربية كلغة ثانية

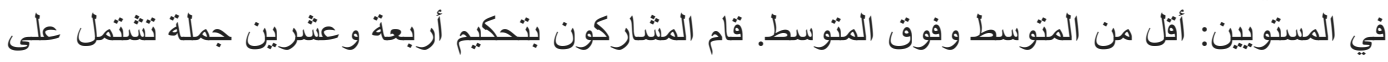

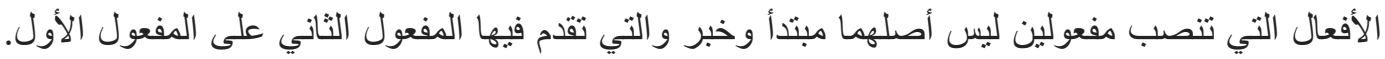

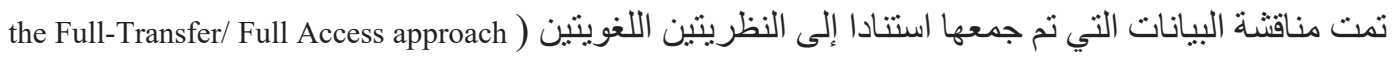
and the Feature Reassembly Hypothesis

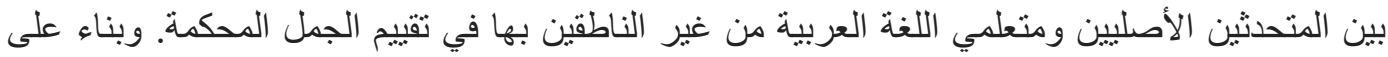
هذه النتيجة يمكن القول بأن متعلمي اللغة الثانية يمكنهم اكتساب تر اكيب اللغنة الثانية الغير اللغوية في لغته 